\title{
High-spin and low-spin iron(II) complexes with facially-coordinated borohydride ligands $\uparrow$
}

\author{
Mark P. Mehn, ${ }^{a, b}$ Steven D. Brown, ${ }^{b}$ Tapan K. Paine, ${ }^{a}$ William W. Brennessel, ${ }^{a}$ Christopher J. Cramer, ${ }^{* c}$ \\ Jonas C. Peters ${ }^{* b}$ and Lawrence Que, Jr. $* a$
}

Received 6th July 2005, Accepted 18th October 2005

First published as an Advance Article on the web 17th November 2005

DOI: 10.1039/b509580h

Rare examples of monometallic high-spin and low-spin $\mathrm{L}_{3} \mathrm{Fe}\left(\mathrm{H}_{3} \mathrm{BH}\right)$ complexes have been characterized, where the two $\mathrm{L}_{3}$ ligands are $\left[\mathrm{Tp}^{\mathrm{Ph} 2}\right]$ and $\left[\mathrm{PhBP}_{3}\right]\left(\left[\mathrm{Tp}^{\mathrm{Ph} 2}\right]=\left[\mathrm{HB}\left(3,5-\mathrm{Ph}_{2} \mathrm{pz}\right)_{3}\right]^{-}\right.$and $\left.\left[\mathrm{PhBP}_{3}\right]=\left[\mathrm{PhB}\left(\mathrm{CH}_{2} \mathrm{PPh}_{2}\right)_{3}\right]^{-}\right)$. The structures are reported wherein the borohydride ligand is facially coordinated to the iron center in each complex. Density functional methods have been employed to explain the bonding in these unusual iron(II) centers. Despite the differences in spin states, short Fe-B distances are observed in both complexes and there is significant theoretical evidence to support a substantial bonding interaction between the iron and boron nuclei. In light of this interaction, we suggest that these complexes can be described as $\left(\mathrm{L}_{3}\right) \mathrm{Fe}\left(\eta^{4}-\mathrm{H}_{3} \mathrm{BH}\right)$ complexes.

\section{Introduction}

Paramagnetic iron hydrides have been invoked as intermediates in the catalytic cycle of hydrogenases and nitrogenases. ${ }^{1}$ Particularly noteworthy is a recent study by Hoffman and co-workers giving evidence for an iron hydride intermediate during nitrogenase turnover. $^{2}$ On the basis of their biophysical ENDOR studies, a high-spin iron hydride intermediate is observed which may correspond to either E2 or E4 in the Thorneley-Lowe kinetic scheme. ${ }^{3}$ Diamagnetic iron hydrides have been extensively studied by several laboratories. ${ }^{4}$ We decided to explore the coordination chemistry of borohydride anions as a possible route to paramagnetic iron hydrides, since in some instances, late transition metal borohydride adducts can serve as precursors to metal hydrides. ${ }^{5}$

Transition metal and lanthanide tetrahydridoborate complexes with varying degrees of stability and reactivity have been reported, ${ }^{6}$ including recent reports of a nickel tetrahydridoborate complex ${ }^{7}$ and a Mo-Fe cluster with terminal borohydride anions. ${ }^{8}$ Although low-spin hexahydridoborate-bridged diiron(II) complexes were recently reported, ${ }^{9}$ mononuclear iron tetrahydridoborate complexes are rare. ${ }^{10,11}$ Prior attempts to isolate the homoleptic borohydride $\mathrm{Fe}\left(\mathrm{BH}_{4}\right)_{2}$ were hindered by complex product mixtures due to the thermal instability of the product(s). ${ }^{11}$ These homoleptic complexes have not been structurally characterized.

${ }^{a}$ Department of Chemistry and Center for Metals in Biocatalysis, University of Minnesota, 207 Pleasant St. SE, Minneapolis, Minnesota, 55455, USA. E-mail: que@chem.umn.edu; Fax: 612624 7029; Tel: 6126240389

${ }^{b}$ Division of Chemistry and Chemical Engineering, Arnold and Mabel Beckman Laboratories of Chemical Synthesis, California Institute of Technology, Pasadena, California, 91125,USA. E-mail: jpeters@caltech.edu; Fax: 626577 4088; Tel: 6263954036

'Department of Chemistry and Supercomputing Institute, University of Minnesota, 207 Pleasant Street SE, Minneapolis, Minnesota, 55455, USA. E-mail: cramer@chem.umn.edu; Fax: 612626 2006; Tel: 6126240859

$\dagger$ Electronic supplementary information (ESI) available: Table comparing selected bond distances and angles for complexes $\mathbf{1}$ and $\mathbf{2}$ as well as the closest literature precedents. See DOI: 10.1039/b509580h
Sterically hindering ligands can lend kinetic stability to reactive inorganic species, and replacement of one $\mathrm{BH}_{4}^{-}$unit with a more sterically encumbering tridentate borate ligand results in a marked increase in the stability of iron(II) borohydride derivatives. To the best of our knowledge, only one structurally characterized, monometallic $\mathrm{Fe}^{\mathrm{II}}$-borohydride complex has been reported, $\left[\mathrm{FeH}\left(\mathrm{H}_{2} \mathrm{BH}_{2}\right)\left\{\mathrm{CH}_{3} \mathrm{C}\left(\mathrm{CH}_{2} \mathrm{PPh}_{2}\right)_{3}\right\}\right]{ }^{10}$

We give an account herein of the synthesis of mononuclear $\left(\mathrm{L}_{3}\right) \mathrm{Fe}^{\mathrm{II}}\left(\mathrm{BH}_{4}\right)$ complexes that are stable at room temperature. The borohydride ligand is facially coordinated to the iron center in both the high-spin complex $\left(\mathrm{L}_{3}=\left[\mathrm{Tp}^{\mathrm{Ph} 2}\right]\right)$ and the low-spin complex $\left(\mathrm{L}_{3}=\left[\mathrm{PhBP}_{3}\right]\right)$. The literature precedent has been to describe these interactions as tridentate or $\eta^{3}$-complexes of borohydride. ${ }^{6,12}$ In general, borohydrides give rise to interesting structural features, and their three-centered two-electron bonding can lead to a variety of hapticities for the borohydride ligand. ${ }^{12}$ Here, a combination of structural, spectroscopic and theoretical methods is used to probe the nature of these species and to address their different spinstates. On the basis of these calculations, we suggest it may be more accurate to describe the binding as an $\eta^{4}$ interaction.

\section{Experimental}

\section{General}

All manipulations were carried out using standard Schlenk or glovebox techniques under a dinitrogen atmosphere. Unless otherwise noted, solvents were deoxygenated and dried by thorough sparging with $\mathrm{N}_{2}$ gas followed by passage through an activated alumina column. Nonhalogenated solvents were tested with a standard purple solution of benzophenone ketyl in tetrahydrofuran to confirm effective oxygen and moisture removal. All reagents were purchased from commercial vendors and used without further purification unless otherwise stated. Elemental analyses were performed either by Atlantic Microlab, Norcross, GA, or by Desert Analytics, Tucson, AZ. Varian $300 \mathrm{MHz}$ spectrometers were used to record the ${ }^{1} \mathrm{H}$ NMR and ${ }^{31} \mathrm{P}$ NMR 
spectra at ambient temperature. ${ }^{1} \mathrm{H}$ chemical shifts were referenced to residual solvent, while ${ }^{31} \mathrm{P}$ NMR chemical shifts were referenced to $85 \% \mathrm{H}_{3} \mathrm{PO}_{4}$ at $\delta 0 \mathrm{ppm} .{ }^{11} \mathrm{~B} \mathrm{NMR}$ were acquired on a JEOL $400 \mathrm{MHz}$ spectrometer, and the chemical shifts were referenced to neat $\mathrm{BF}_{3} \cdot \mathrm{OEt}_{2}$ at $\delta 0 \mathrm{ppm}$. IR measurements were taken on $\mathbf{1}$ as $\mathrm{KBr}$ pellets using an Avatar 320 FTIR spectrometer controlled by EZ Omnic software set at $4 \mathrm{~cm}^{-1}$ resolution, or in the case of 2 were obtained with a $\mathrm{KBr}$ solution cell using a Bio-Rad Excalibur FTS 3000 spectrometer controlled by Bio-Rad Merlin Software (v. 2.97) set at $4 \mathrm{~cm}^{-1}$ resolution.

Magnetic measurements on $\mathbf{1}$ were recorded using a Quantum Designs SQUID magnetometer running Magnetic Property Measurement System Rev. 2 software. Data were recorded at $5000 \mathrm{G}$. The sample was suspended in the magnetometer in a plastic straw sealed under nitrogen with Lilly No. 4 gel caps. Loaded samples were centered within the magnetometer using the DC centering scan at $35 \mathrm{~K}$ and $5000 \mathrm{G}$. Data were acquired at 4-30 K (one data point every $2 \mathrm{~K}$ ) and 30-300 $\mathrm{K}$ (one data point every $5 \mathrm{~K}$ ). The magnetic susceptibility was adjusted for diamagnetic contributions using the constitutive corrections of Pascal's constants. The molar magnetic susceptibility $\left(\chi_{\mathrm{m}}\right)$ was calculated by converting the calculated magnetic susceptibility $(\chi)$ obtained from the magnetometer to a molar susceptibility (using the multiplication factor $\{$ (molecular weight) $/[$ (sample weight)(field strength)] $\}$ ). The mass used for 1 was the unsolvated neutral complex. Effective magnetic moments were calculated using eqn (1).

$$
\mu_{\mathrm{eff}}=\left(7.997 \chi_{\mathrm{m}} T\right)^{1 / 2}
$$

\section{Metal complex syntheses}

$\left[\mathbf{T} \mathbf{p}^{\mathrm{Ph} 2}\right] \mathbf{F e}\left(\mathrm{H}_{3} \mathbf{B H}\right)$, 1. A solution of $\mathrm{Fe}\left(\mathrm{ClO}_{4}\right)_{2} \cdot 6 \mathrm{H}_{2} \mathrm{O}(0.20 \mathrm{~g}$, $0.5 \mathrm{mmol})$ in $\mathrm{CH}_{3} \mathrm{CN}(5 \mathrm{~mL})$ was added dropwise to a mixture of the $\mathrm{Tp}^{\mathrm{Ph} 2}$ ligand $^{13}(0.35 \mathrm{~g}, 0.5 \mathrm{mmol})$ and $\mathrm{KBH}_{4}(0.027 \mathrm{~g}$, $0.5 \mathrm{mmol})$. The resulting white suspension was stirred overnight at RT. The solvent was then removed in vacuo and the crude white powder was dissolved in $5 \mathrm{~mL} \mathrm{CH} \mathrm{Cl}_{2}$. The solution was filtered and the filtrate was kept for slow vapor diffusion of ether. After standing unperturbed overnight an off-white crystalline solid was

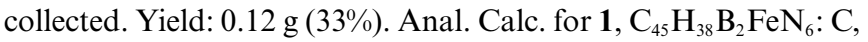
73.01; H, 5.17; N, 11.35. Found: C, 72.25; H, 5.09; N, 11.26; Cl, $1.12 \%$. Trace chloride is always observed in the elemental analysis despite repeated attempts to further purify the sample.

$\left[\mathbf{P h B P} \mathbf{P}_{3}\right] \mathbf{F e}\left(\mathbf{H}_{3} \mathbf{B H}\right), 2$. This compound was synthesized by metathesis of the previously reported iron chloride complex $\left[\mathrm{PhBP}_{3}\right] \mathrm{FeCl}^{14}(0.10 \mathrm{~g}, 0.13 \mathrm{mmol})$ with a large excess $(30 \times)$ of $\mathrm{NaBH}_{4}(0.15 \mathrm{~g}, 3.9 \mathrm{mmol})$ in THF $(5 \mathrm{~mL})$ at room temperature. After stirring overnight, the solution was filtered and the volatiles were removed under reduced pressure. The resultant dark red solid was taken up in benzene and crystallized from vapor diffusion of petroleum ether (bp 35-60 ${ }^{\circ} \mathrm{C}$ ) into the solution. Yield: $0.095 \mathrm{~g}$, (97\%). Anal. Calc. for $2, \mathrm{C}_{45} \mathrm{H}_{45} \mathrm{~B}_{2} \mathrm{FeP}_{3}$ : C, 71.47; H, 6.00. Found: $\mathrm{C}, 71.07 ; \mathrm{H}, 6.09 \% .{ }^{1} \mathrm{H}$ NMR $\left(300 \mathrm{MHz}, \mathrm{C}_{6} \mathrm{D}_{6}\right): \delta 8.10(\mathrm{~d}$, $J=7.5 \mathrm{~Hz}, 2 \mathrm{H}) ; 7.69$ (t, $J=7.5 \mathrm{~Hz}, 2 \mathrm{H}) ; 7.49$ (br s, $12 \mathrm{H}) ; 7.45$ (overlaps with resonance at $7.49 \mathrm{ppm}, \mathrm{t}, J=7.5 \mathrm{~Hz}, 1 \mathrm{H}) ; 6.72(\mathrm{~m}$, $18 \mathrm{H}) ; 1.54$ (s, 6H); -11.8 (br s, 4H). ${ }^{31} \mathrm{P}\left\{{ }^{1} \mathrm{H}\right\} \mathrm{NMR}(121.4 \mathrm{MHz}$, $\mathrm{C}_{6} \mathrm{D}_{6}$ ): $\delta 76.2$ (s). ${ }^{11} \mathrm{~B}\left\{{ }^{1} \mathrm{H}\right\}$ NMR (128.3 MHz, $\mathrm{C}_{6} \mathrm{D}_{6}$ ): $\delta 22.2$ (br s,
$\left.\mathrm{BH}_{4}^{-}\right) ;-12.9\left(\mathrm{~s}, \mathrm{PhB}\left(\mathrm{CH}_{2} \mathrm{PPh}_{2}\right)_{3}{ }^{-}\right)$. IR $\left(\mathrm{KBr} / \mathrm{C}_{6} \mathrm{H}_{6}\right): 2603 \mathrm{~cm}^{-1}$ (w); $2575 \mathrm{~cm}^{-1}(\mathrm{~m})$.

\section{X-Ray diffraction analysis}

$\left[\mathrm{Tp}^{\mathrm{Ph} 2}\right] \mathrm{Fe}\left(\mathrm{H}_{3} \mathrm{BH}\right)$ (1) was characterized using $\mathrm{X}$-ray diffraction at the X-ray Crystallographic Laboratory at the University of Minnesota. A crystal of 1 was attached to the tip of a glass capillary on a Siemens SMART Platform CCD diffractometer for data collection at 173(2) $\mathrm{K}$ using graphite-monochromated Mo-K $\alpha$ $\left(\lambda=0.71073 \AA\right.$ ). X-Ray diffraction studies on $\left[\mathrm{PhBP}_{3}\right] \mathrm{Fe}\left(\mathrm{H}_{3} \mathrm{BH}\right)$ (2) were carried out in the Beckman Institute Crystallographic Facility at Caltech on a Bruker Smart 1000 CCD diffractometer. The crystal was mounted on a glass fiber with Paratone $\mathrm{N}$ oil. A summary of the crystallographic details for both $\mathbf{1}$ and $\mathbf{2}$ is given in Table 1. All non-hydrogen atoms were refined anisotropically, and hydrogen atoms except those attached to boron atoms were placed in ideal positions and refined as riding atoms with relative isotropic displacement parameters. The hydride atoms were found from the E-map and refined independently. The final full matrix least squares refinement converged to $R 1=0.0281$ and $w R 2=$ 0.0648 for 1 and $R 1=0.0515$ and $w R 2=0.0838$ for 2 .

CCDC reference numbers: 250211 for $\mathbf{1}$ and 250212 for $\mathbf{2}$.

For crystallographic data in CIF or other electronic format see DOI: $10.1039 /$ b509580h

\section{Computational methods}

Models for $\mathbf{1}$ and $\mathbf{2}$ in which the phenyl rings on the ligands were replaced by $\mathrm{H}$ atoms were fully optimized at the $m$ PWPW91 level ${ }^{15}$ of density functional theory. ${ }^{16} \mathrm{~A}$ basis set was employed that combined the CEP-31G effective core potential and associated basis functions on $\mathrm{Fe}^{17}$ with the polarized McLean-Chandler basis set on $\mathrm{P}^{18}$ and the 6-311G(d,p) basis set ${ }^{19}$ on all other atoms (for a total of 421 and 301 basis functions, respectively, for the simplified analogs of $\mathbf{1}$ and 2). The optimized Kohn-Sham determinantal wave functions were used for the computation of Mayer bond orders $^{20}$ and in the depiction of molecular orbitals.

Table 1 Summary of crystallographic data for $\left[\mathrm{Tp}^{\mathrm{Ph} 2}\right] \mathrm{Fe}\left(\mathrm{H}_{3} \mathrm{BH}\right),(\mathbf{1})$ and $\left[\mathrm{PhBP}_{3}\right] \mathrm{Fe}\left(\mathrm{H}_{3} \mathrm{BH}\right)$, (2)

\begin{tabular}{lll}
\hline & $\mathbf{1}$ & $\mathbf{2}$ \\
\hline Chemical formula & $\mathrm{C}_{45} \mathrm{H}_{38} \mathrm{~B}_{2} \mathrm{FeN}_{6}$ & $\mathrm{C}_{45} \mathrm{H}_{55} \mathrm{~B}_{2} \mathrm{FeP}_{3}$ \\
$M_{\mathrm{r}}$ & 740.28 & 756.19 \\
Space group & $R 3 c$ & $C 2 / c$ \\
$a / \AA$ & $16.185(1)$ & $39.226(4)$ \\
$b / \AA$ & $16.185(1)$ & $13.006(1)$ \\
$c / \AA$ & $25.833(3)$ & $16.141(2)$ \\
$a /{ }^{\circ}$ & 90 & 90 \\
$\beta /{ }^{\circ}$ & 90 & $110.695(4)$ \\
$\gamma /{ }^{\circ}$ & 120 & 90 \\
$V / \AA^{3}$ & $5860.7(9)$ & $7703.1(1)$ \\
$Z$ & 6 & 8 \\
$D_{\mathrm{c}} / \mathrm{g} \mathrm{cm}^{-3}$ & 1.258 & 1.304 \\
$T / \mathrm{K}$ & $173(2)$ & $100(2)$ \\
$\mu / \mathrm{cm}^{-1}$ & 4.26 & 5.48 \\
$R 1 / w R 2^{a}(I>2 \sigma(I))$ & $0.0281 / 0.0621$ & $0.0515 / 0.0785$ \\
$R 1 / w R 2($ all data $)$ & $0.0357 / 0.0648$ & $0.0971 / 0.0838$ \\
& & \\
${ }^{a} R 1=\sum\left\|F_{\mathrm{o}}|-| F_{\mathrm{c}}\right\| / \sum / F_{\mathrm{o}} \mid$. & $w R 2=\left[\sum\left[w\left(F_{\mathrm{o}}{ }^{2}-F_{\mathrm{c}}{ }^{2}\right)^{2}\right] / \sum\left[w\left(F_{\mathrm{o}}{ }^{2}\right)^{2}\right]\right]^{1 / 2}$ \\
where $w=q / \sigma^{2}\left(F_{\mathrm{o}}{ }^{2}\right)+(a P)^{2}+b P$. & \\
\hline
\end{tabular}




\section{Results and discussion}

Treatment of iron(II) perchlorate with the scorpionate ligand, potassium hydrotris(3,5-diphenylpyrazol-1-yl)borate $\mathrm{K}\left[\mathrm{Tp}^{\mathrm{Ph} 2}\right]$ and $\mathrm{KBH}_{4}$ in acetonitrile results in the formation of an offwhite solid, which upon recrystallization from methylene chloridediethyl ether gives rise to clear colorless blocks of $\left[\mathrm{Tp}^{\mathrm{Ph} 2}\right] \mathrm{Fe}\left(\mathrm{BH}_{4}\right)$ (1). Metathesis of $\left[\mathrm{PhBP}_{3}\right] \mathrm{FeCl}^{14}$ with an excess of $\mathrm{NaBH}_{4}$ in $\mathrm{THF}$ results in the formation of a deep red solution. After removal of the sodium salts, recrystallization of the crude red powder affords ruby red crystals of $\left[\mathrm{PhBP}_{3}\right] \mathrm{Fe}\left(\mathrm{BH}_{4}\right)$ (2). Unlike the reported synthesis of $\left[\mathrm{FeH}\left(\mathrm{H}_{2} \mathrm{BH}_{2}\right)\left\{\mathrm{CH}_{3} \mathrm{C}\left(\mathrm{CH}_{2} \mathrm{PPh}_{2}\right)_{3}\right\}\right]$, we do not observe an intermediate dinuclear $\mu_{3}$-trihydride in either synthesis. ${ }^{10}$ In contrast to $\mathrm{Fe}\left(\mathrm{BH}_{4}\right)_{2},{ }^{11}$ both $\mathbf{1}$ and $\mathbf{2}$ are thermally stable at room temperature.

Single-crystal X-ray diffraction studies confirmed $\mathbf{1}$ and $\mathbf{2}$ to be $\left(\mathrm{L}_{3}\right) \mathrm{Fe}^{\mathrm{II}}\left(\mathrm{BH}_{4}\right)$ complexes (Fig. 1, Table 2), with the absence of counterions in both structures providing support for the iron(II) oxidation state assignment. Both the monoanionic ancillary ligand $\left(\left[\mathrm{Tp}^{\mathrm{Ph} 2}\right]\right.$ or $\left.\left[\mathrm{PhBP}_{3}\right]\right)$ and the $\mathrm{BH}_{4}{ }^{-}$anion are coordinated facially to the iron center in each complex, generating an effective $C_{3}$ axis of symmetry that contains the ligand boron atom, the iron atom, and the boron atom of the borohydride in each case. The $\mathrm{Tp}^{\mathrm{Ph} 2}$ complex 1, in fact, lies on a crystallographic three-fold axis, making only a third of the molecule crystallographically unique. Additionally, the iron centers of both $\mathbf{1}$ and $\mathbf{2}$ can be described as having a trigonally distorted octahedral geometry (for 1: B2$\mathrm{Fe}-\mathrm{N} 11126.10(4)^{\circ}$ and $\mathrm{N} 11-\mathrm{Fe}-\mathrm{N} 11^{\prime} 88.81(5)^{\circ}$; for 2 : B2-Fe-P $\left.125.09(5)^{\circ}, \mathrm{P}_{\mathrm{av}}-\mathrm{Fe}-\mathrm{P}_{\mathrm{av}} 90.21(2)^{\circ}\right)$.

The Fe-N11 bond length in $\mathbf{1}(2.106(1) \AA)$ is comparable to those found for $\left[\mathrm{Tp}^{\mathrm{Ph} 2}\right] \mathrm{Fe}\left(\kappa^{2}-\mathrm{O}_{2} \mathrm{CPh}\right)\left(\mathrm{Fe}-\mathrm{N}_{\mathrm{av}} 2.111(1) \AA\right),{ }^{21}$ consistent with a high-spin iron(II) center. On the other hand, the $\mathrm{Fe}-\mathrm{P}_{\mathrm{x}}$ bond lengths of $\mathbf{2}\left(\mathrm{Fe}-\mathrm{P}_{\mathrm{av}} 2.2061(4) \AA\right)$ are comparable to the $\mathrm{Fe}-\mathrm{P}_{\mathrm{x}}$ distances in either the low-spin pseudo-tetrahedral imide $\left\{\left[\mathrm{PhBP}_{3}\right] \mathrm{Fe}^{\mathrm{II}} \equiv \mathrm{NAd}\right\}^{-}\left(\mathrm{Fe}-\mathrm{P}_{\text {av }} 2.142(6) \AA\right)$ or the low-spin octahedral species $\left\{\left[\mathrm{PhBP}_{3}\right] \mathrm{Fe}\left(\mathrm{NCCH}_{3}\right)_{3}\right\}\left(\mathrm{FeCl}_{4}\right)\left(\mathrm{Fe}-\mathrm{P}_{\mathrm{av}} 2.280(1)\right.$ $\AA) .{ }^{22,23}$ Accordingly the $\mathrm{BH}_{4}{ }^{-}$ligand in each case is structurally distinct. The Fe-H3 distance of 1.99(2) $\AA$ in $\mathbf{1}$ is significantly longer than the average $\mathrm{Fe}-\mathrm{H}$ distance of 1.60(2) $\AA$ in $\mathbf{2}$.
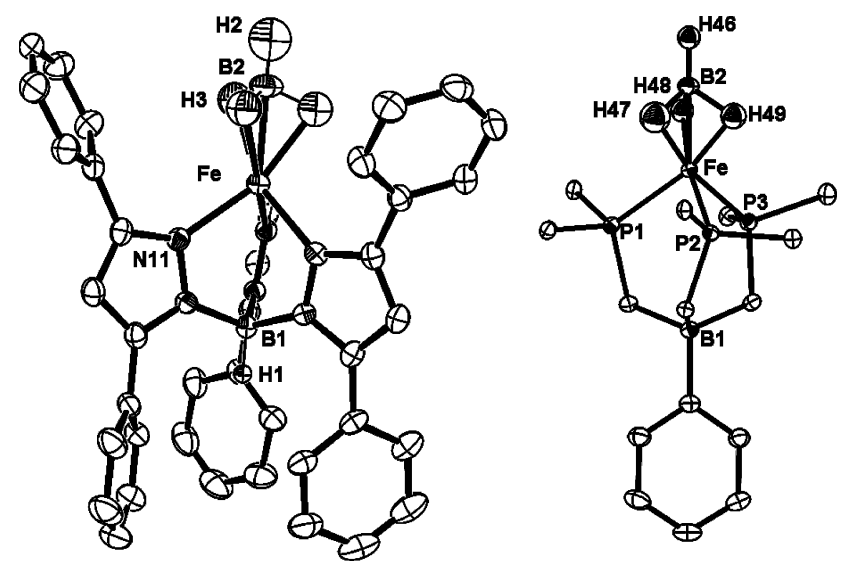

Fig. 1 ORTEP plot of $\left.\left[\mathrm{Tp}^{\mathrm{Ph} 2}\right] \mathrm{Fe}\left(\mathrm{H}_{3} \mathrm{BH}\right)\right](\mathbf{1})$ and $\left[\mathrm{PhBP}_{3}\right] \mathrm{Fe}\left(\mathrm{H}_{3} \mathrm{BH}\right)$ (2) showing $50 \%$ probability thermal ellipsoids and the labelling scheme for selected atoms. All hydrogen atoms, except those attached to boron atoms, as well as a one 3-phenyl group on $\mathbf{1}$ and all but the ipso-carbons of the phenyl rings on $\mathbf{2}$ have been omitted for clarity.
Table 2 Selected bond distances and angles for $\left[\mathrm{Tp}^{\mathrm{Ph} 2}\right] \mathrm{Fe}\left(\mathrm{H}_{3} \mathrm{BH}\right),(\mathbf{1})$, and $\left[\mathrm{PhBP}_{3}\right] \mathrm{Fe}\left(\mathrm{H}_{3} \mathrm{BH}\right),(2)$

\begin{tabular}{|c|c|c|c|}
\hline \multicolumn{4}{|c|}{ Complex 1} \\
\hline $\mathrm{Fe}-\mathrm{B} 2$ & $2.084(4)$ & B2-Fe-N11 & $126.10(4)$ \\
\hline $\mathrm{Fe}-\mathrm{H} 3$ & $1.99(2)$ & $\mathrm{N} 11-\mathrm{Fe}-\mathrm{N} 11^{\prime}$ & $88.81(5)$ \\
\hline B2-H3 & $1.16(2)$ & $\mathrm{B} 2-\mathrm{Fe}-\mathrm{H} 3$ & $33.1(7)$ \\
\hline B2-H2 & $0.98(5)$ & $\mathrm{Fe}-\mathrm{B} 2-\mathrm{H} 3$ & $69(1)$ \\
\hline \multirow[t]{2}{*}{$\mathrm{Fe}-\mathrm{N} 11$} & $2.106(1)$ & $\mathrm{Fe}-\mathrm{B} 2-\mathrm{H} 2$ & $180.000(3)$ \\
\hline & & $\mathrm{H} 3-\mathrm{B} 2-\mathrm{H} 2$ & $111(1)$ \\
\hline \multicolumn{4}{|c|}{ Complex 2} \\
\hline $\mathrm{Fe}-\mathrm{B} 2$ & $1.855(2)$ & $\mathrm{B} 2-\mathrm{Fe}-\mathrm{P} 1$ & $124.24(5)$ \\
\hline $\mathrm{Fe}-\mathrm{H} 47$ & $1.57(2)$ & $\mathrm{B} 2-\mathrm{Fe}-\mathrm{P} 2$ & $126.54(5)$ \\
\hline $\mathrm{Fe}-\mathrm{H} 48$ & $1.62(2)$ & $\mathrm{B} 2-\mathrm{Fe}-\mathrm{P} 3$ & $124.50(5)$ \\
\hline $\mathrm{Fe}-\mathrm{H} 49$ & $1.61(2)$ & $\mathrm{P} 1-\mathrm{Fe}-\mathrm{P} 2$ & $92.06(2)$ \\
\hline B2-H47 & $1.20(2)$ & $\mathrm{P} 2-\mathrm{Fe}-\mathrm{P} 3$ & $89.03(2)$ \\
\hline B2-H48 & $1.18(2)$ & P3-Fe-P1 & $89.53(2)$ \\
\hline B2-H49 & $1.26(2)$ & $\mathrm{B} 2-\mathrm{Fe}-\mathrm{H} 47$ & $39.9(7)$ \\
\hline B2-H46 & $1.07(2)$ & $\mathrm{B} 2-\mathrm{Fe}-\mathrm{H} 48$ & $39.0(5)$ \\
\hline $\mathrm{Fe}-\mathrm{P} 1$ & $2.2119(4)$ & $\mathrm{B} 2-\mathrm{Fe}-\mathrm{H} 49$ & $41.9(6)$ \\
\hline $\mathrm{Fe}-\mathrm{P} 2$ & $2.2088(4)$ & $\mathrm{Fe}-\mathrm{B} 2-\mathrm{H} 47$ & $57.2(8)$ \\
\hline \multirow[t]{6}{*}{$\mathrm{Fe}-\mathrm{P} 3$} & $2.1977(4)$ & $\mathrm{Fe}-\mathrm{B} 2-\mathrm{H} 48$ & $59.5(7)$ \\
\hline & & $\mathrm{Fe}-\mathrm{B} 2-\mathrm{H} 49$ & $58.7(7)$ \\
\hline & & $\mathrm{Fe}-\mathrm{B} 2-\mathrm{H} 46$ & $178.6(9)$ \\
\hline & & $\mathrm{H} 46-\mathrm{B} 2-\mathrm{H} 47$ & $124(1)$ \\
\hline & & H46-B2-H48 & $121(1)$ \\
\hline & & H46-B2-H49 & $120(1)$ \\
\hline
\end{tabular}

Solid-state magnetic susceptibility data for 1 were obtained from 4-300 K by SQUID magnetometry (Fig. 2). The plot of $\chi_{\mathrm{m}} T v s$. temperature is consistent with a high-spin iron(II) $(S=2)$ center. Curie-Weiss behavior was verified by a plot of $\chi_{\mathrm{m}}{ }^{-1}$ vs. $T$ (inset). From 10 to $300 \mathrm{~K}$ the average value of $\mu_{\text {eff }}$ is $5.07 \mu_{\mathrm{B}}$. This value unambiguously establishes the high-spin character of the iron(II) center in $\mathbf{1}$. Not surprisingly the value deviates from the spin-only value of $4.899 \mu_{\mathrm{B}}$, as expected for an electronic configuration with a spin-orbit coupling contribution.

Interestingly, the $\mathrm{Fe}-\mathrm{B} 2$ distances in both complexes are rather short. The Fe-B2 distance in 1 of 2.084(4) A is less than the Fe-N11 distance. The geometry observed in the high-spin iron(II) complex $\mathbf{1}$ is closely related to that observed in $\left[\mathrm{Tp}^{*}\right] \mathrm{Ni}\left(\mathrm{H}_{3} \mathrm{BH}\right)$ which also has a short Ni-B distance of 2.048(5) $\AA$. $^{7}$ These nickel and iron

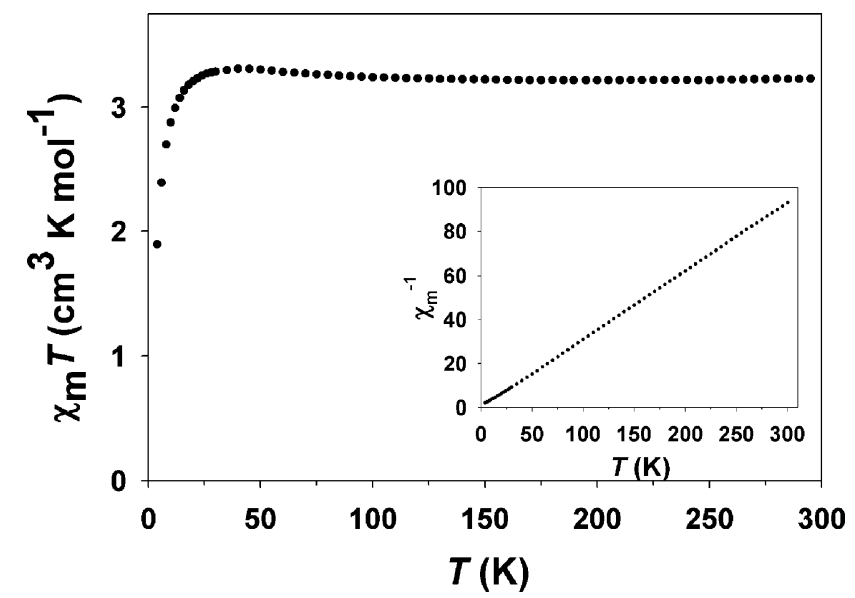

Fig. 2 SQUID magnetometry data for 1 plotted as $\chi_{\mathrm{m}} T$ vs. $T$. The inset shows the same data plotted as $\chi_{\mathrm{m}}{ }^{-1} v s . T$ (slope $=0.311$, intercept $=0.025$, $R^{2}=0.9999$ ). 
complexes exhibit similar distortions of the borohydride anion. In both cases the coordinated borohydride is essentially tetrahedral, showing only a slight elongation of the $\mathrm{B}-\mathrm{H}$ bonds that bridge the boron and iron nuclei. The corresponding Fe-B2 distance in $\mathbf{2}$ is $1.855(2) \AA$, consistent with the expected decrease in ionic radius for a low-spin metal center. To the best of our knowledge, the closest structural analogues to these complexes are $\left[\left\{\mathrm{Fe}\left(\mathrm{PEt}_{3}\right)_{3}\right\}_{2}(\mu-\right.$ $\left.\mathrm{H})_{6} \mathrm{~B}\right]^{+}$and $\left[(\text {triphos }) \mathrm{Fe}\left(\mathrm{H}_{3} \mathrm{BH}_{3}\right) \mathrm{Fe}(\text { triphos })\right]^{+} .{ }^{9}$ These low-spin complexes exhibits similarly short $\mathrm{Fe}-\mathrm{B}$ bond distances (1.903(3), 1.913(3) and 1.912(1) A, respectively). A table comparing the other bond distances and angles of these complexes is included in the ESI. $\dagger$

One of the key features in determining the hapticity of borohydride anion binding to transition metal ions has been the vibrational features of the ligated borohydride. ${ }^{6}$ IR analysis of 1 (Fig. 3(A)) shows a number of interesting features. The feature observed at $2603 \mathrm{~cm}^{-1}$ is insensitive to deuteration of the borohydride and therefore has been assigned to the $v(\mathrm{~B}-\mathrm{H})$ of the $\left[\mathrm{Tp}^{\mathrm{Ph} 2}\right]$ ligand. A broad band observed at $2430 \mathrm{~cm}^{-1}$ is sensitive to isotopic substitution. The deuterated species exhibits a reproducible broad feature near $1824 \mathrm{~cm}^{-1}$ under a number of other vibrational bands in the $\mathrm{Fe}\left(\mathrm{D}_{3} \mathrm{BD}\right)$ complex. This broad band also appears in the difference spectrum. This mode has been tentatively assigned to the $v(\mathrm{~B}-\mathrm{H})_{\text {distal }}$, and is in good agreement with published $v(\mathrm{~B}-\mathrm{H})$ vibrations and theory. Hooke's law predicts a $v(\mathrm{~B}-\mathrm{D}) / v(\mathrm{~B}-\mathrm{H})$ ratio of 0.74 and we observe a ratio of 0.75 for this mode. Another broad band appears at $2088 \mathrm{~cm}^{-1}$ which we ascribe to the $v(\mathrm{~B}-\mathrm{H})_{\text {proximal }}$ mode. Using the ratio determined for the terminal $\mathrm{B}-\mathrm{H}$ stretch, the $v(\mathrm{~B}-\mathrm{D})_{\text {proximal }}$ for $\left[\mathrm{Tp}^{\mathrm{Ph} 2}\right] \mathrm{Fe}\left(\mathrm{D}_{3} \mathrm{BD}\right)$ is estimated to lie near $1540 \mathrm{~cm}^{-1}$, a region obscured by strong ligand vibrations. Literature precedent suggests that for a tridentate binding of $\mathrm{BH}_{4}{ }^{-}$, three $A_{1}$ bands should be observed (between 2450-2600, 2100-2200 and 1200-1250 $\mathrm{cm}^{-1}$, respectively). ${ }^{6} \mathrm{We}$ do not observe the lowest energy mode for $\mathbf{1}$ and believe it is obscured

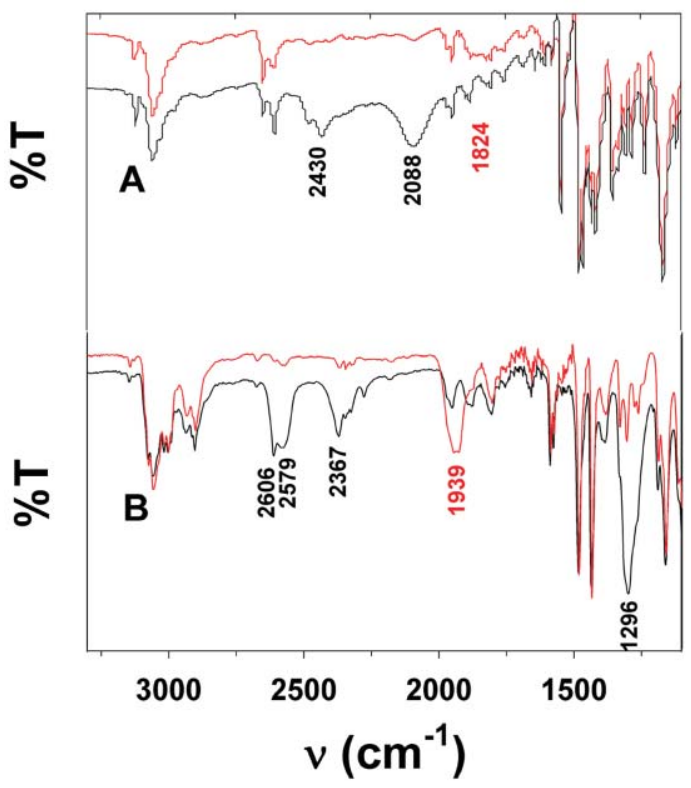

Fig. 3 IR spectra of (A) $\left[\mathrm{Tp}^{\mathrm{Ph} 2}\right] \mathrm{Fe}\left(\mathrm{H}_{3} \mathrm{BH}\right)$ and (B) $\left[\mathrm{PhBP}_{3}\right] \mathrm{Fe}\left(\mathrm{H}_{3} \mathrm{BH}\right)$. The natural abundance spectra are shown in black and the spectra of the $\mathrm{BD}_{4}{ }^{-}$ complexes are shown in red. by vibrational modes of the ancillary ligand. The higher energy bands appear at the low end of the given frequency range. This may have to do with the open-shell nature of $\mathbf{1}$. The low-spin borohydride adduct 2 shows three vibrations at 2606, 2367 and $1296 \mathrm{~cm}^{-1}$. These modes respond to isotopic substitution of the borohydride ligand. The highest energy band shifts to $1939 \mathrm{~cm}^{-1}$ while the other two vibrations are lost in the peaks observed for the $\left[\mathrm{PhBP}_{3}\right]$ ligand framework. The assignments are analogous to those reported in the literature ${ }^{6}$ and consistent with a facially coordinated $\mathrm{BH}_{4}{ }^{-}$ligand.

There are several ways to imagine the $\mathrm{Fe}-\left(\mathrm{H}_{3} \mathrm{BH}\right)$ interaction. For instance, it may be viewed as arising from three separate three-centered, two-electron interactions between each iron center and the $\mathrm{B}-\mathrm{H}$ bonds, isolobal with $\eta^{5}$-cyclopentadienide, halide and oxide. ${ }^{24}$ Given the short $\mathrm{Fe}-\mathrm{B}$ distances and the convention of describing the hapticity as $\eta^{3}-\mathrm{BH}_{4}$ group, ${ }^{6}$ it was unclear to us whether the $\mathrm{B}$ atom was involved in bonding with the metal center in either $\mathbf{1}$ or $\mathbf{2}$. Alternatively, it may not interact with the boron center at all, simply utilizing the hydrides to bridge the two nuclei (consistent with the $\eta^{3}$ designation previously used). To gain additional insight into the nature of the bonding between the iron and borohydride moiety, mPWPW91 density functional calculations were undertaken for simplified models of high-spin 1 and low-spin $\mathbf{2}$. All of the phenyl rings in both $\mathbf{1}$ and $\mathbf{2}$ were replaced with hydrogen atoms for these computational studies. Structures having $C_{3 \mathrm{v}}$ and $C_{3}$ symmetry, respectively, were found as minima, with structural parameters generally in good agreement with the experimental data (Table 3). Bond orders were computed by the method of Mayer ${ }^{20}$ using the optimized density matrices for these structures (Table 3). This method has previously been shown to be robust for the description of multicoordinate bonding between transition metals and associated ligands. ${ }^{25}$

Analysis of the Kohn-Sham molecular orbitals rationalizes the computed bond orders in the two systems (Fig. 4). The highest energy doubly occupied orbital in both $\mathbf{1}$ and $\mathbf{2}$ belongs to the totally symmetric irreducible representation and mixes the $\mathrm{Fe}$ $\mathrm{d}_{z^{2}}$ with both a boron hybrid and all four of the hydrogenic 1s orbitals. Bonding interactions in this orbital contribute to the significant $\mathrm{Fe}-\mathrm{H}_{\text {proximal }}$ bond orders. The orbital we show has an antibonding interaction between the boron and iron centers, albeit a weak one. (There is an almost perfect cancellation of the two orbitals magnitudes so that the B-Fe part appears almost nonbonding.) The bonding interaction appears significantly lower in the orbital manifold and has positive overlap of the boron $\mathrm{p}$ with the iron $\mathrm{d}_{z^{2}}$ orbital. The four singly occupied orbitals in quintet 1 constitute two degenerate sets each belonging to the e irreducible representation. In singlet $\mathbf{2}$, the energy separation

Table 3 Theoretical bond lengths and Mayer bond orders

\begin{tabular}{|c|c|c|c|c|}
\hline & \multicolumn{2}{|c|}{ Bond length/Å } & \multicolumn{2}{|c|}{ Bond order } \\
\hline & $\mathbf{1}^{a}$ & $2^{a}$ & 1 & 2 \\
\hline $\mathrm{Fe}-\mathrm{B} 2$ & $2.052(2.084)$ & $1.840(1.855)$ & 0.56 & 0.88 \\
\hline $\mathrm{Fe}-\mathrm{H}_{\text {proximal }}$ & $1.978(1.99)$ & $1.688(1.60)$ & 0.31 & 0.46 \\
\hline $\mathrm{Fe}-\mathrm{N} / \mathrm{Fe}-\mathrm{P}$ & $2.100(2.106)$ & $2.206(2.212)$ & 0.40 & 0.96 \\
\hline B-- $\mathrm{H}_{\text {proximal }}$ & $1.262(1.16)$ & $1.331(1.21)$ & 0.69 & 0.50 \\
\hline $\mathrm{B}-\mathrm{H}_{\text {distal }}$ & $1.200(0.98)$ & $1.190(1.07)$ & 0.93 & 0.93 \\
\hline
\end{tabular}

${ }^{a}$ Observed crystallographic distances in parentheses. 

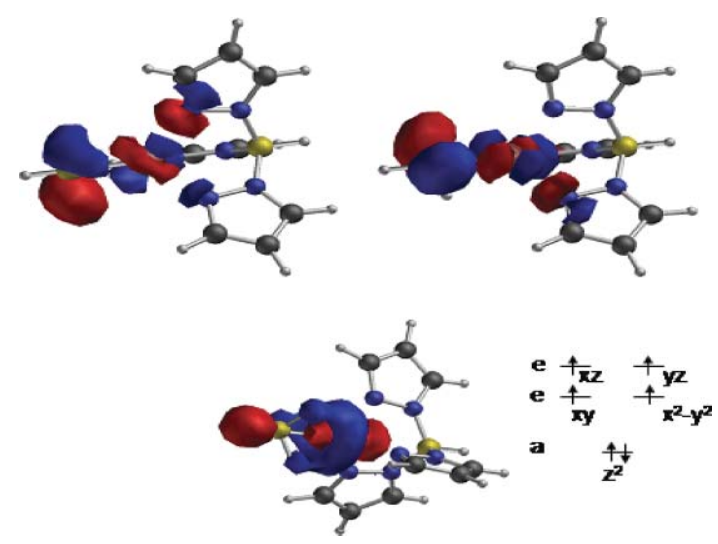

Fig. 4 Frontier DFT MOs (the a symmetry HOMO and highest energy $e$ set) and a qualitative splitting diagram for $\mathbf{1}$ (orbitals for $\mathbf{2}$ are qualitatively very similar). Note that the orientation of the model in the lowest orbital is somewhat different from the other two in order to improve clarity.

between these two orbital sets is larger (because of the stronger ligand field enforced by the phosphine donors as opposed to the pyrazole donors) and the orbitals of the lower energy set are doubly occupied while those of the higher energy set are empty. The members of the higher energy set, also depicted in Fig. 4, are dominated by $\pi^{*}$ antibonding interactions between the $\mathrm{d}_{x z}$ and $\mathrm{d}_{y z}$ orbitals and s orbitals on the borohydride $\mathrm{H}$ atoms towards which they are directed. The singly occupied nature of these orbitals in 1 compared to $\mathbf{2}$, where they are empty, explains the substantially greater $\mathrm{Fe}-\mathrm{H}_{\text {proximal }}$ bond order seen in the latter. Not surprisingly, this difference in $\mathrm{Fe}-\mathrm{H}$ bond orders is balanced by a smaller B$\mathrm{H}_{\text {proximal }}$ bond order in $\mathbf{2}$ than in $\mathbf{1}$. This analysis is also consistent with the closer approach of the borohydride, and especially its proximal $\mathrm{H}$ atoms, to $\mathrm{Fe}$ in $\mathbf{2}$ compared with $\mathbf{1}$. The remaining two singly occupied orbitals in $\mathbf{1}$, which are doubly occupied in 2, are not depicted: the $\mathrm{Fe} \mathrm{d}_{x y}$ and $\mathrm{d}_{x^{2}-y^{2}}$ AOs contribute to these MOs and show no particular interactions with the borohydride ligand (which is incapable of $\delta$ bonding). Rather, these orbitals are $\pi^{*}$ antibonding between $\mathrm{Fe}$ and the ligand nitrogen atoms in $\mathbf{1}$, but $\pi$ bonding between $\mathrm{Fe}$ and the ligand phosphorus atoms in 2 . This in part explains the lower $\mathrm{Fe}-\mathrm{P} / \mathrm{Fe}-\mathrm{N}$ bond orders seen for $\mathbf{1}$ compared to $\mathbf{2}$. Theory is thus consistent with designating the interaction as an $\mathrm{Fe}-\eta^{4}$-borohydride coordination.

In conclusion, we have demonstrated that borohydride adducts of iron can be generated and isolated. The spin state of the iron center can be controlled via the ancillary ligand. Alteration of the ligand field results in compensatory changes in the observed bond distances as well as the theoretical bond orders for the $\left(\mathrm{L}_{3}\right) \mathrm{Fe}\left(\eta^{4}\right.$ $\mathrm{H}_{3} \mathrm{BH}$ ) complex. Studies are underway to examine the effect of spin state on the reactivity of these novel complexes, as paramagnetic iron hydrides are postulated to be reactive intermediates in the catalytic cycles of nitrogenases and hydrogenases. ${ }^{1-3}$

\section{Acknowledgements}

This work was supported by the National Institutes of Health (GM-33162 to L. Q. and GM-070757 to J. C. P.) and the National
Science Foundation (CHE-0203346 to C. J. C.) We thank Larry Henling of the Beckman Institute Crystallographic Facility at Caltech for help with refinement of 2.

\section{References}

1 B. K. Burgess and D. J. Lowe, Chem. Rev., 1996, 96, 2983; R. K. Thauer, A. R. Klein and G. C. Hartmann, Chem. Rev., 1996, 96, 3031.

2 R. Y. Igarashi, M. Laryukhin, P. C. Dos Santos, H.-I. Lee, D. R. Dean, L. C. Seefeldt and B. M. Hoffman, J. Am. Chem. Soc., 2005, 127, 6231.

3 R. N. F. Thorneley and D. J. Lowe, in Molybdenum Enzymes, ed. T. G. Spiro, John Wiley \& Sons, New York, 1985; vol. 7, p. 221.

4 C. Tard, X. Liu, S. K. Ibrahim, M. Bruschi, L. De Gioia, S. C. Davies, X. Yang, L.-S. Wang, G. Sawers and C. J. Pickett, Nature, 2005, 433, 610; M. Y. Darensbourg, E. J. Lyon, X. Zhao and I. P. Georgakaki, Proc. Natl. Acad. Sci. USA, 2003, 100, 3683; C. A. Boyke, T. B. Rauchfuss, S. R. Wilson, M.-M. Rohmer and M. Bénard, J. Am. Chem. Soc., 2004, 126, 15151; E. J. Daida and J. C. Peters, Inorg. Chem., 2004, 43, 7474; J. M. Smith, R. J. Lachicotte and P. L. Holland, J. Am. Chem. Soc., 2003, 125, 15752; D. E. Linn, Jr. and S. G. Gibbins, Inorg. Chem., 1997, 36, 3461 .

5 Transition Metal Hydrides, ed. A. Dedieu, VCH, New York, 1992; Recent Advances in Hydride Chemistry, ed. M. Peruzzini and R. Poli, Elsevier, Amserdam, 2001.

6 T. J. Marks and J. R. Kolb, Chem. Rev., 1977, 77, 263; B. D. James and M. G. H. Wallbridge, Prog. Inorg. Chem., 1970, 11, 99; M. Ephritikhine, Chem. Rev., 1997, 97, 2193; P. J. Fischer, V. G. Young, Jr. and J. E. Ellis, Angew. Chem., Int. Ed., 2000, 39, 189.

7 P. J. Desrochers, S. LeLievre, R. J. Johnson, B. T. Lamb, A. L. Phelps, A. W. Cordes, W. Gu and S. P. Cramer, Inorg. Chem., 2003, 42, 7945.

8 M. Koutmos and D. Coucouvanis, Inorg. Chem., 2004, 43, 6508.

9 A. C. Hillier, H. Jacobsen, D. Gusev, H. W. Schmalle and H. Berke, Inorg. Chem., 2001, 40, 6334; G. Guilera, G. S. McGrady, J. W. Steed and N. Kaltsoyannis, New J. Chem., 2004, $28,444$.

10 C. A. Ghilardi, P. Innocenti, S. Midollini and A. Orlandini, J. Organomet. Chem., 1982, 231, C78; C. A. Ghilardi, P. Innocenti, S. Midollini and A. Orlandini, J. Chem. Soc., Dalton Trans., 1985, 605.

11 G. W. Schaeffer, J. S. Roscoe and A. C. Stewart, J. Am. Chem. Soc., 1956, 78, 729; G. Monnier, Ann. Chim. (Paris), 1957, $2,14$.

12 R. W. Parry and G. Kodama, Coord. Chem. Rev., 1993, 128, 245; Z. Xu and Z. Lin, Coord. Chem. Rev., 1996, 156, 139; P. Dapporto, S. Midollini and L. Sacconi, Inorg. Chem., 1975, 14, 1643.

13 N. Kitajima, K. Fujisawa, C. Fujimoto, Y. Moro-oka, S. Hashimoto, T. Kitagawa, K. Toriumi, K. Tatsumi and A. Nakamura, J. Am. Chem. Soc., 1992, 114, 1277.

14 S. D. Brown, T. A. Betley and J. C. Peters, J. Am. Chem. Soc., 2003, $125,322$.

15 J. P. Perdew and Y. Wang, Phys. Rev. B: Condens. Matter, 1986, 33, 8800; J. P. Perdew, in Electronic Structure of Solids '91', ed. P. Ziesche and H. Eschrig, Akademie Verlag, Berlin, Germany, 1991; C. Adamo and V. Barone, J. Chem. Phys., 1998, 108, 664.

16 C. J. Cramer, Essentials of Computational Chemistry, John Wiley \& Sons, Chichester, UK, 2004.

17 W. J. Stevens, M. Krauss, H. Basch and P. G. Jasien, Can. J. Chem., $1992,70,612$.

18 A. D. McLean and G. S. Chandler, J. Chem. Phys., 1980, 72, 5639.

19 W. J. Hehre, L. Radom, P. v. R. Schleyer and J. A. Pople, Ab Initio Molecular Orbital Theory, Wiley, New York, 1986.

20 I. Mayer, Chem. Phys. Lett., 1983, 97, 270.

21 M. P. Mehn, K. Fujisawa, E. L. Hegg and L. Que, Jr., J. Am. Chem. Soc., 2003, 125, 7828.

22 S. D. Brown and J. C. Peters, J. Am. Chem. Soc., 2005, 127, 1913.

23 J. Duimstra, J. C. Peters, unpublished results.

24 M. Mancini, P. Bougeard, R. C. Burns, M. Mlekuz, B. G. Sayer, J. I. A. Thompson and M. J. McGlinchey, Inorg. Chem., 1984, 23, 1072.

25 E. C. Scherer, C. R. Kinsinger, B. L. Kormos, J. D. Thompson and C. J. Cramer, Angew. Chem., Int. Ed., 2002, 41, 1953. 